\title{
Wind conditions and ventilation in high-rise long street models
}

\author{
Jian Hang ${ }^{\mathrm{a}}$, Yuguo $\mathrm{Li}^{\mathrm{a}, *}$, Mats Sandberg ${ }^{\mathrm{b}}$, Leif Claesson ${ }^{\mathrm{b}}$ \\ ${ }^{a}$ Department of Mechanical Engineering, The University of Hong Kong, Haking Wong Building, Pokfulam Road, Hong Kong, China \\ ${ }^{\mathrm{b}}$ KTH Research School, Laboratory of Ventilation and Air Quality, University of Gävle, 80176 Gävle, Sweden
}

\section{A R T I C L E I N F O}

\section{Article history:}

Received 27 August 2009

Received in revised form

11 November 2009

Accepted 26 November 2009

\section{Keywords:}

Numerical simulation

Wind tunnel

High-rise long street

Flow rate

Air change rate $(A C H)$

Turbulent exchange

\begin{abstract}
A B S T R A C T
We regarded high-rise cities as obstacles and channels to wind. We first studied wind conditions and ventilations in idealized high-rise long street models experimentally and numerically with a constant street width $(W=30 \mathrm{~mm})$, variable street heights $(H=2 W, 2.5 W, 3 W, 4 W)$, variable street lengths $(L=47.4 \mathrm{~W}, 79 \mathrm{~W}, 333 \mathrm{~W}, 667 \mathrm{~W})$ and a parallel approaching wind. The flow rates penetrating into windward entries are a little larger than the reference flow rate in the far upstream free flow through the same area with windward entries in all models. The stream-wise velocity decreases along the street as some air leaves upwardly across street roofs. Near the leeward entry, there is a downward flow which brings some air into the street and results in an accelerating process. In the neighborhood scale long streets $(L=47.4 \mathrm{~W}$ and $79 \mathrm{~W}$ ), wind in taller streets is stronger and the ventilation is better than a lower one. For the city scale long streets $(L=333 W$ and $667 W$ ), a constant flow region exists where the vertical velocity is zero and the stream-wise velocity remains constant. In such regions, turbulent fluctuations across the street roof are more important to air exchange than vertical mean flows. In a taller street, the process to establish the constant flow conditions is longer and the normalized balanced horizontal flow rate is smaller than those in a lower street. In the city scale long streets, the turbulence exchange rate can be $5-10$ times greater than the mean flow rate.
\end{abstract}

Crown Copyright @ 2009 Published by Elsevier Ltd. All rights reserved.

\section{Introduction}

Wind conditions in urban areas are very important in removing or dispersing the airborne pollutants in urban canopies or providing cleaner external (rural) air. In the main urban areas of Hong Kong such as North Point, Causeway Bay, Central, and Sheung Wan (see Fig. A1 in Appendix A), the street aspect ratio (building height/street width, i.e. $H / W$ ) is mostly more than $2-4$, sometimes exceeds 6 and even reaches 10 . The easterly prevailing wind in the atmospheric boundary layer $(\mathrm{ABL})$ may be seriously blocked in such packed highrise urban areas. A fraction of air may be driven out of the high-rise urban canopy (see Fig. A2a).

Britter and Hanna [1] summarized studies of the flow in urban areas into four scales, i.e. the regional scale (up to 100 or $200 \mathrm{~km}$ ), the city scale (up to 10 or $20 \mathrm{~km}$ ), the neighborhood scale (up to 1 or $2 \mathrm{~km}$ ) and the street scale (less than 100-200 m). The regional scale [2] regards a city as a roughness of the atmosphere boundary layer and emphasizes the regional effect of geographic and meteorological conditions on urban wind environment and regional pollutant transportation in a large scale. The minimum grid size is

\footnotetext{
* Corresponding author. Tel.: +852 2859 2625; fax: +852 28585415

E-mail address: liyg@hku.hk (Y. Li).
}

several hundred meters without any flow information in a street/ building scale. Many investigations study the local turbulent flow in a street scale or in a neighborhood scale, i.e. around isolated buildings [3], in low-rise [4-6] and high-rise street canyon models $[7,8]$ and within finite groups of buildings [9-12]. These studies used experimental measurements and/or numerical simulations by large-eddy simulation (LES) or by Reynolds-averaged NavierStokes (RANS) turbulence models, as reviewed by previous researchers $[1,13,14]$.

Our ultimate aim is to study wind conditions in a high-rise packed city like Hong Kong in a city scale (up to $10 \mathrm{~km}$ ). General numerical techniques have difficulty in studying urban airflows in a city scale because simulating airflows around thousands of buildings requires an unaffordable grid number. For example, a high-rise building array in a neighborhood scale with hundreds of buildings generally requires tens of millions of grids and that in a city scale with thousands of buildings requires billions of grids. We regard the city with high-rise buildings and narrow streets as blockages and pathways to the approaching wind. In this paper, we first study wind conditions in high-rise long street models in a neighborhood scale and in a city scale with a parallel approaching wind (see Fig. A2a and b). In addition, the grid number in long street models can be technically reduced because there are no secondary streets and the grid size along the long street can be

0360-1323/\$ - see front matter Crown Copyright (c) 2009 Published by Elsevier Ltd. All rights reserved. doi:10.1016/j.buildenv.2009.11.019 
large where the stream-wise gradients of flow variables is small. The difference between these two models is that there are no building height variations and no interactions at street intersections in the long street model.

When the street is long in contrast to its width and the approaching wind is perpendicular to the street axis, the flow can be treated as two-dimensional (2D). Many studies were performed to study different vortex structures in different 2D street canyons [4-8], probably because that the pollutants tend to stay a relatively long time in such situation. Actually if the street is very long with a parallel approaching wind, the pollutants may accumulate along the street and the air in its downstream region may also be seriously polluted. Soulhac et al. [15] developed a theoretical model for studying wind profile in low-rise long streets $(H / W=1$ or 2$)$ with a parallel approaching wind. The long street models in this study were assumed to be embedded in the fully developed region of a long city and subsequently there were no end effects. Hang et al. [16] performed both wind tunnel measurements and numerical simulations to study the flow mechanism and ventilation flow rates through a low-rise long street model $(H / W=1, L / W=22)$. It was found that a flow balance may exist in a very long low-rise street when the vertical velocity component is nearly equal to zero and its horizontal flow rate is a constant. When wind is blowing at angle which is not parallel or perpendicular to the street axis, a helical flow structure can be observed along the street [14,15]; i.e. a combination of a longitudinal flow along the street and a mixing recirculation flow.

This paper focuses on wind conditions and ventilation in the high-rise long street models when the approaching wind is parallel to the street axis. The street aspect ratios are more than 2 and the street length is from a neighborhood scale to a city scale. We are more interested in what happens in a city scale long street. For example, the east-westerly straight Chang-a street in Beijing is $42 \mathrm{~km}$ long and some east-westerly streets along Hong Kong Island also reach $10 \mathrm{~km}$. Such long street models would reveal the distance that wind can penetrate into the street, whether the wind can blow through the entire long street or it may stop at somewhere, and what is the impact of the building height and the street length.

\section{Methodology}

Idealized models which consist of five long streets were studied (see Fig. 1a) by assuming that the approaching wind blows parallel to the long streets. In all the idealized models, the width of streets $(W)$ and width of buildings $(B)$ are kept constant $(W=30 \mathrm{~mm}$, $B=40 \mathrm{~mm}$ ), but the uniform height $(H)$ of streets and length $(L)$ of streets vary in which the street aspect ratio $(H / W)$ is $2,2.5,3$ or 4 , and street length ratio $(L / W)$ is $47.4,79,333$ or 667 . Computational fluid dynamic (CFD) simulations were carried out to reproduce those wind tunnel tests. These models are in 1:500 to the full scale construction, i.e. corresponding to the street width of $15 \mathrm{~m}$ and the street length of $0.7 \mathrm{~km}, 1.2 \mathrm{~km}, 5 \mathrm{~km}$ or $10 \mathrm{~km}$ at the full scale. The two length scales of $47.4 W$ and $79 W$ (or $0.7 \mathrm{~km}$ and $1.2 \mathrm{~km}$ at the full scale) belong to the neighborhood scale, and the other two scales of $333 W$ and $667 W$ (or $5 \mathrm{~km}$ and $10 \mathrm{~km}$ at the full scale) correspond to the city scale. There are totally 16 test cases. The cases are described by Long [aspect ratio $H / W$, the street length ratio $L / W$ ]. That is, Long $[2,47.4]$ will refer to a long street model in which the aspect ratio is 2 and the street length ratio is 47.4 . Besides this case, the other 15 cases include Long [2.5, 47.4], Long [3, 47.4], Long [4, 47.4], Long $[2,79]$, Long $[2.5,79]$, Long $[3,79]$, Long $[4,79]$, and some city scale long street models, i.e. Long [2, 333], Long [2.5, 333], Long [3, 333], Long [4, 333], Long [2, 667], Long [2.5, 667], Long [3, 667], Long $[4,667]$. In this study, both CFD simulations and wind tunnel measurements were employed for the neighborhood scale long street models $(L / W=47.4$ or 79$)$ but for the city scale long street models $(L / W=333$ or 667$)$, only CFD simulations were performed.

All the measurements were carried out in an aerodynamics boundary layer wind tunnel (closed-circuit type) which is located at the Laboratory of Ventilation and Air Quality, University of Gävle, Sweden. The working section is $11 \mathrm{~m}$ long, $3 \mathrm{~m}$ wide and $1.5 \mathrm{~m}$ high. There was no roughness element on the wind tunnel floor. The velocity and turbulence intensity were measured by a hotwire anemometry. For the measurement at each point, the measuring frequency is $100 \mathrm{~Hz}$ and the measurement time is $30 \mathrm{~s}$.

For the idealized models with a length of $47.4 \mathrm{~W}$ and $79 W$ (i.e. Cases Long [2, 47.4], Long [2.5, 47.4], Long [3, 47.4], Long [4, 47.4], Long $[2,79]$, Long $[2.5,79]$, Long $[3,79]$ and Long $[4,79])$, as shown in Fig. 1b, we measured vertical profiles (from wind tunnel floor to a height of $10 W$ above wind tunnel floor) at Point $A$ (in Street A) and Point C (in Street C) (i.e. locating at $15.4 \mathrm{~W}$ from the leeward street opening of each long street), as well as the horizontal profile along the street axis of Street $A$ at the height of $z=W$ above the wind tunnel floor. Fig. 2 shows that vertical profiles of velocity and turbulence intensity at Point $A$ and Point $C$ are almost the same, so we only put forward the study of street A (surrounded by the dot line in Fig. 1b) in CFD simulations such that symmetric half of Street A domain was adopted so as to reduce calculation time.

For CFD simulations, the CFD code Fluent 6.3 was used with both the standard $k-\varepsilon[17]$ and the RNG $k-\varepsilon$ turbulence model [18] to solve the incompressible steady and isothermal turbulent flow field. The computation domain in Long $[3,47.4]$ is shown in Fig. 3a as an example. At the domain inlet, turbulent kinetic energy $k$ and its dissipation rate $\varepsilon$ were calculated by vertical profiles of the stream-wise velocity $\bar{u}$ (or the velocity $V$ ) and turbulence intensity $I$ measured in the far upstream free flow (Fig. 3b), using the equations of $k=1.5(I \bar{u})^{2}, \varepsilon=C_{\mu}^{3 / 4} k^{3 / 4} / l_{t}$, where $C_{\mu}$ is a constant $(0.09)$ and $l_{t}$ is the turbulent characteristic length scale.

We should note that, the hotwire is only sensitive to velocity components which are perpendicular to it (i.e. the vertical $(z)$ velocity $\bar{w}$ and the stream-wise $(x)$ velocity $\bar{u}$, see Fig. 3c). So the velocity measured by the hotwire is actually the value of $\sqrt{\bar{u}^{2}+\bar{w}^{2}}$. In the upstream free flow, both span-wise $(\bar{v})$ and vertical $(\bar{w})$ velocity components are zero, so the measured stream-wise velocity $(\bar{u})$ equals the local velocity $\left(V=\sqrt{\bar{u}^{2}+\bar{v}^{2}+\bar{w}^{2}}\right)$. Within the long streets, because the hotwire in this study always locates at the street center where the span-wise $(y)$ velocity $\bar{v}$ is zero, the measured velocity components $\sqrt{\bar{u}^{2}+\bar{w}^{2}}$ also equals to the local velocity $\left(V=\sqrt{\bar{u}^{2}+\bar{v}^{2}+\bar{w}^{2}}\right)$.

Fig. 3d shows the grid generation near the long street model of Long $[3,47.4]$. The grid size in the stream-wise direction $(d x)$ can be large in regions far from the two street ends where the stream-wise gradients are small. For example, the maximum grid size $(d x)$ is $5 W$ in the city scale long street of Case Long $[3,667]$. The number of hexahedral cells generated for all CFD simulations were 151,950 to 258,804 . The minimum mesh size near walls was $0.07 \mathrm{~W}$ where no slip wall boundary condition with standard wall functions [19] was used. We used a zero normal gradient for all boundary variables at the domain outlet, the domain roof and symmetry boundaries.

To quantify the variation of air motion, we normalized streamwise ( $x$-axis) and vertical ( $z$-axis) velocity components by streamwise velocity which was measured at the same height of the far upstream plane. Volumetric flow rates through street openings, along the street and across the street roof were used to evaluate the capacity of pollutant dilution and air exchange by wind effect. And a reference flow rate $\left(Q_{\infty}\right)$ calculated by Eq. (1) was developed. Then Eq. (1) was used in Eq. (2) for giving the normalized mean flow rates across street openings and the street roof in Eq. (3) to give the normalized effective flow rate due to turbulent exchange 
a
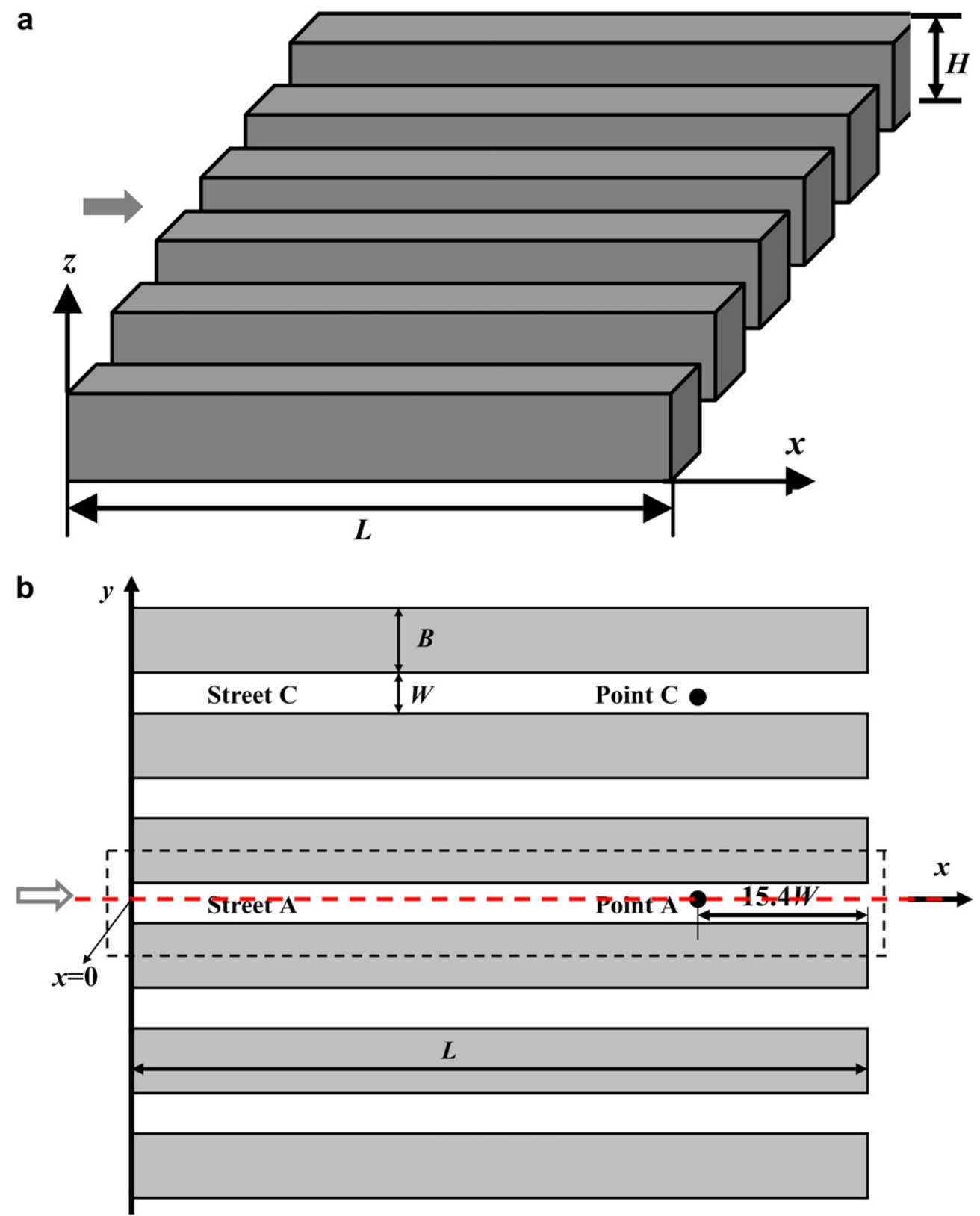

Fig. 1. Views of long street models: (a) Three-dimensional (3D), (b) two-dimensional (2D).

across the street roof. These factors were confirmed to be important by Hang et al. [16]:

$$
\begin{aligned}
& Q_{\infty}=W \int_{0}^{H} \bar{u}_{\infty}(z) d z \\
& Q^{*}=\int_{A} \vec{V} \cdot \vec{n} d A / Q_{\infty} \\
& Q_{\text {turb } \pm}^{*}= \pm \int_{A_{\text {roof }}} 0.5 \sigma_{w} d A / Q_{\infty}
\end{aligned}
$$

where in Eq. (1), $\bar{u}_{\infty}(z)$ is the measured vertical profile of streamwise velocity in the far upstream free flow as illustrated in Fig. 3b, and $W$ is the street width of street entries. The reference flow rate $Q_{\infty}$ is the flow rate of the far upstream free flow through the same area with street entries. When the height $(H)$ of street entries increases (i.e. taller buildings), the reference flow rate also increases. In Eq. (2), $\vec{V}$ is velocity vector, $\vec{n}$ is the normal direction of openings or the street roof, $A$ is the area of the street roof or openings. In Eq. (3), $Q_{\text {turb } \pm}^{*}$ represents the normalized effective flow rates across the street roof due to the upward and downward turbulence fluctuations. $A_{\text {roof }}$ is the area of the street roof. $\sigma_{\mathrm{w}}\left(\sqrt{\overline{w^{\prime} w^{\prime}}}=\sqrt{2 k / 3}\right)$ is the vertical velocity fluctuation across the street roof based on the approximation of isotropic turbulence $\left(u^{\prime}=v^{\prime}=w^{\prime}\right)$ where $u^{\prime}, v^{\prime}, w^{\prime}$ are the stream-wise, span-wise, vertical velocity fluctuations and $k$ is turbulent kinetic energy. The constant 0.5 means that the effective upward and downward flow rates due to turbulence fluctuation across the street roof are the same value (i.e. $0.5 \sigma_{\mathrm{w}}$ for upward flux and $0.5 \sigma_{\mathrm{w}}$ for downward flux). 

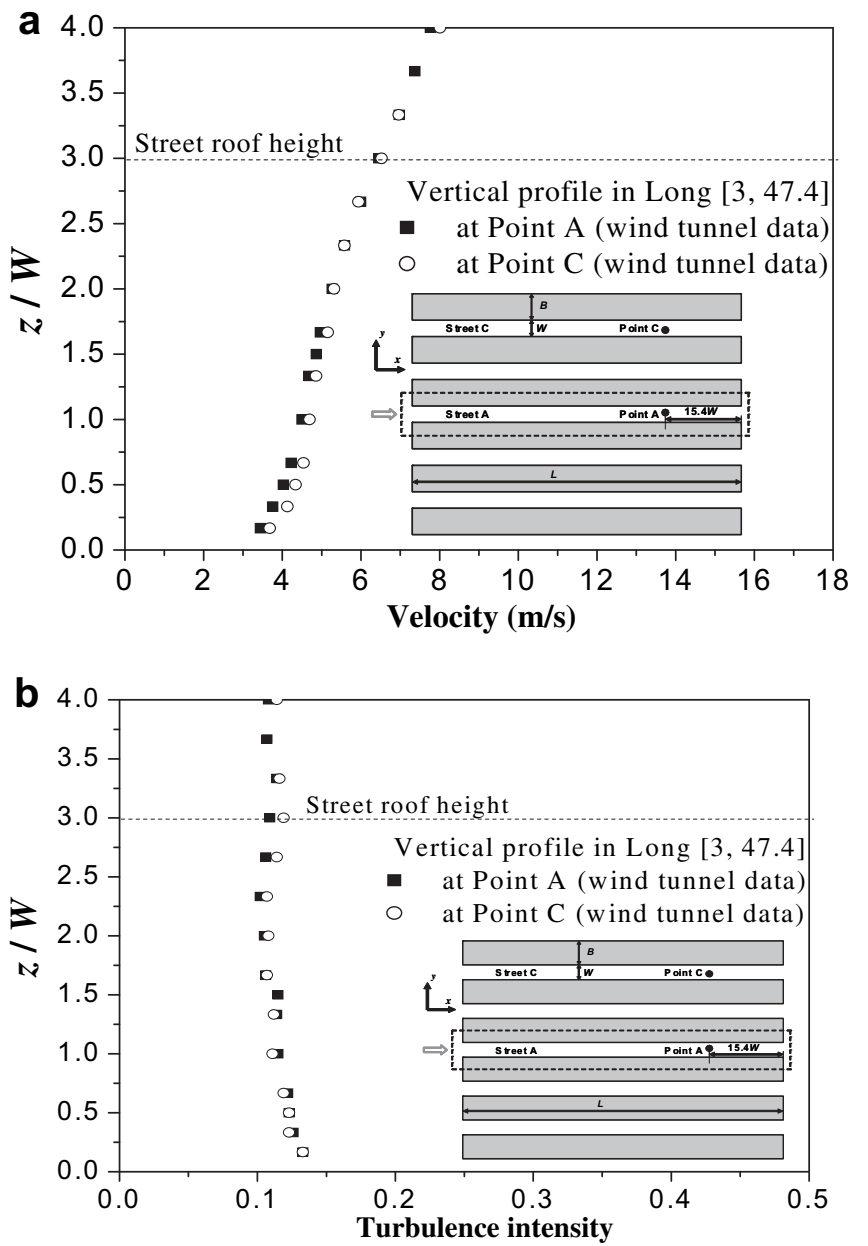

Fig. 2. Vertical profiles of (a) velocity and (b) turbulence intensity at Point A and $\mathrm{C}$ in Long $[3,47.4]$. Each test case is identified here as Long [aspect ratio $H / W$, street length ratio $L / W]$.

As reported in Hang et al. [16], there is a region with constant flow conditions in a long street low-rise model. In such a region, the pressure gradients may be very small. The downward transport of momentum by turbulent shear stress acts as an important motor of the forward flow. The opposing frictions on street walls and the street ground mainly contribute to the removal of momentum along the streets. In the region where the flow are fully developed, the above two factors may be kept constant along the street. To display this condition in a sufficiently long street, we utilized the horizontal profile of the downward turbulent shear stress component $\tau_{x z}$ (see Eq. (4)). In regions where the flow is fully developed, not only the flow variables of velocity components and turbulent quantities but also the shear stress components keep constant in the stream-wise direction.

$\tau_{x z}=\left(\mu+\mu_{t}\right) \frac{d \bar{u}}{d z}$

where $\mu$ and $\mu_{t}$ are molecular viscosity and turbulent viscosity.

From the mass balance, the total flow rate entering $\left(Q_{\text {in }}\right)$ and leaving $\left(Q_{\text {out }}\right)$ the street volume through street entries and the street roof by mean flows should be the same. We named them as $Q_{\mathrm{T}}$ :

$Q_{\mathrm{T}}=Q_{\text {in }}=Q_{\text {out }}$
The air change rate (air exchange per hour for a control volume$A C H)$ is widely used in indoor ventilation problems to show the ventilation capacity of a room by airflows through supplies and exhausts, windows and doors. We also used it to study ventilation in high-rise long street models. The air change rates due to the total mean flow rates and the effective flow rate due to turbulent exchange across the street roof were defined as

$A C H=3600 Q_{\mathrm{T}} / \mathrm{vol}$

$A C H_{\text {turb }}=3600 Q_{\text {turb }} /$ vol

where vol is the control volume of the long street, 3600 means that $1 \mathrm{~h}$ is $3600 \mathrm{~s}$.

\section{Results and discussion}

\subsection{Evaluation of CFD simulations by wind tunnel data}

Fig. 4 shows the evaluation of CFD simulation results by wind tunnel data using some example horizontal profiles (see Fig 4a and b) along the street axis at the height of $z=W$ or vertical profiles (see Fig. 4c and d) at Point A. We find that both the standard $k-\epsilon$ model and the RNG $k-\epsilon$ model can predict the velocity profiles generally well, however the turbulence intensity is under-predicted along the street. The following discussion and analysis will be based on the results from the RNG $k-\epsilon$ model only. As illustrated in Fig. 4a and $b$, both numerical results and wind tunnel data reveal the process of wind flowing through the long street models $(x / W=0$ is the windward street entry). The velocity first decreases in the windward side $(x / W<0)$ of the long street models, then an accelerating process exists across the windward street entry, followed by a velocity reduction as deeper into the long street models, and finally the velocity increases a little near the leeward opening of the long street models. The turbulence intensity in the leeward side of the long street models (i.e. in the wake region) is very large. The following analysis will discuss the flow mechanisms and wind conditions in such long street models in more detail.

\subsection{Effect of aspect ratio in neighborhood scale long street models $(L / W=47.4)$}

The questions to be answered here are whether the flow can be fully developed in the neighborhood scale long street models and its flow mechanisms as well as the effect of the street aspect ratio.

Fig. 5a and b show the three-dimensional (3D) streamline near the windward and leeward street entries in Long $[3,47.4]$. Fig. $5 \mathrm{c}$ and $\mathrm{d}$ show the horizontal profiles of the normalized stream-wise and vertical velocity along the street centerlines at roof levels (i.e. $2 W, 3 W$ or $4 W$ ) and at the height of $z=W$ in Long $[2,47.4]$, Long $[3,47.4]$ and Long $[4,47.4]$. The location of $x / W=0$ is the windward street entry. As approaching the windward entry, wind is blocked and displaced by the solid city, so in the region of $x / W$ from -10 to -1 , the stream-wise velocity decreases (see Fig. 5c). In front of the windward street entry, Fig. 5a shows that wind penetrates into the windward entry and there is an upward flow across the street roof. Across the windward street entry $(x / W$ from -1 to 0.5$)$, Fig. $5 c$ shows an acceleration of the stream-wise velocity and this acceleration process is the strongest in Long [4, 47.4] and the smallest in Long [2, 47.4]. The normalized stream-wise velocity at the windward street entry $(x=0)$ is a little more than 1.0 and its maximum value appears at about $x=0.5 W$. Fig. $5 \mathrm{~d}$ shows that the vertical velocity near the windward street entry $(x=0)$ is very large at the roof levels $(z=H=2 W, 3 W$ or $4 W)$ and is relatively small at the height of 
a

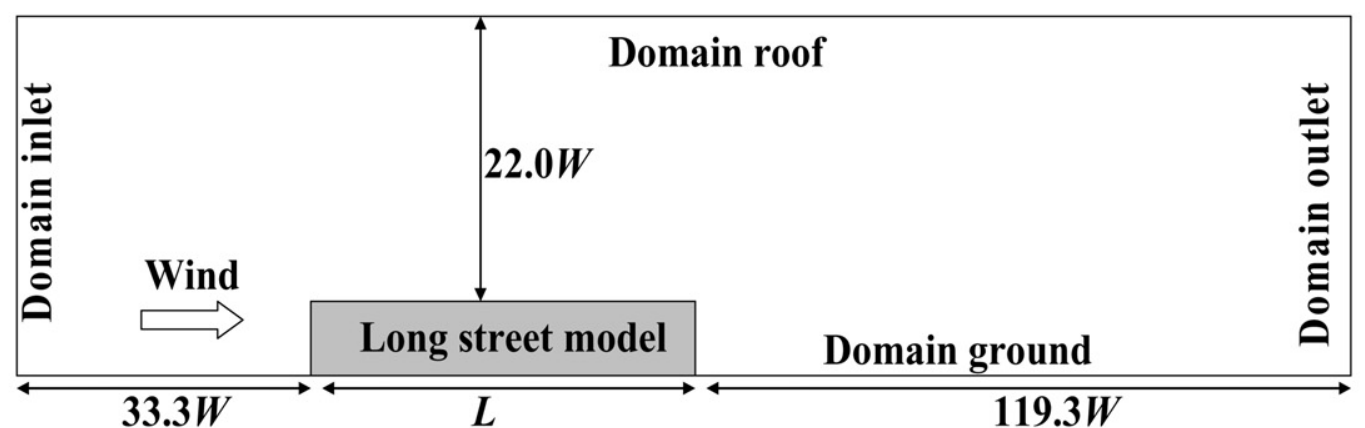

b

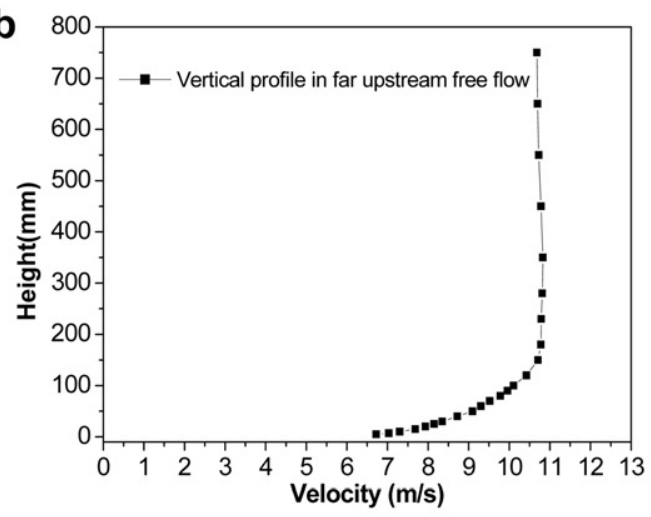

C
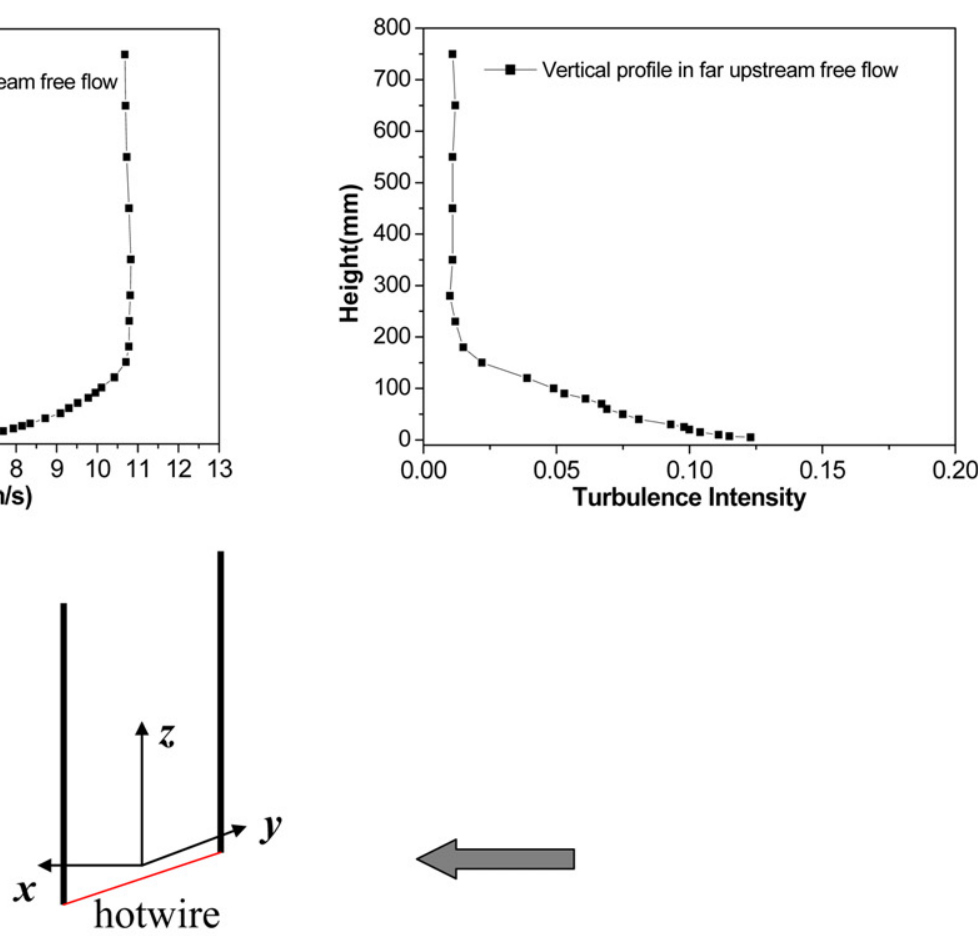

d
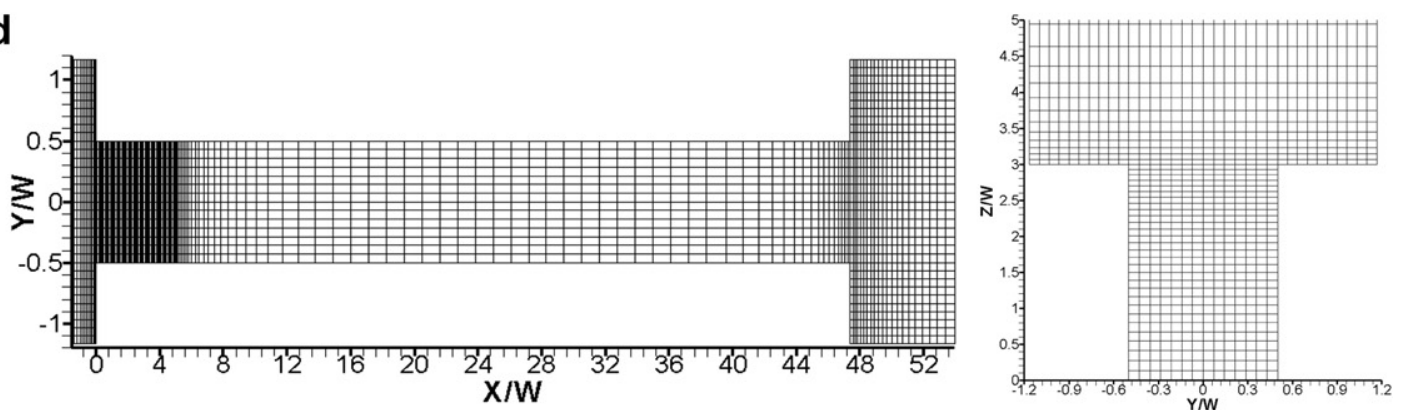

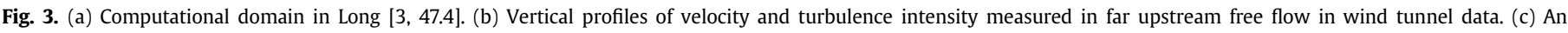
illustration of measuring velocity using the hotwire. (d) The grid generation near the long street model of Long [3, 47.4].

$z=W$. We also find that the positive vertical velocity at the street roof level $(z=4 W)$ of Long $[4,47.4]$ is larger than that at the roof level $(z=2 W)$ in Long $[2,47.4]$, however at the height of $z=W$ near the windward entry $(x=0)$, the vertical velocity in Long [4, $47.4]$ is less than that in Long [2, 47.4]. To explain such kinds of phenomenon near the street windward entry, Fig. 5e-g show 2D streamline and distribution of static pressure, the stream-wise velocity and the vertical velocity in the plane of $x=-0.003 \mathrm{~W}$ (i.e. near the windward street entry) in Long [2, 47.4] and Long [4, 47.4]. The approaching airflow is stagnated by the windward walls and static pressure in the stagnation region is high. Fig. 5e shows that the maximum pressure on the taller windward walls in Long $[4,47.4]$ is about 55 pa which exceeds that in Long $[2$, 47.4] (i.e. $45 \mathrm{~Pa}$ ). In addition, the center of stagnation region in Long $[4,47.4]$ is at about $z=3.2 \mathrm{~W}$ which is much taller than that in Long $[2,47.4]$ (about $z=1.6 W$ ). The stagnated airflow on the windward walls is diverged into three kinds of flows along the wall surfaces due to the pressure gradient, i.e. an upward flow from the stagnation region to the roof level, a lateral flow from the stagnation region to the street entry, a downward flow from 

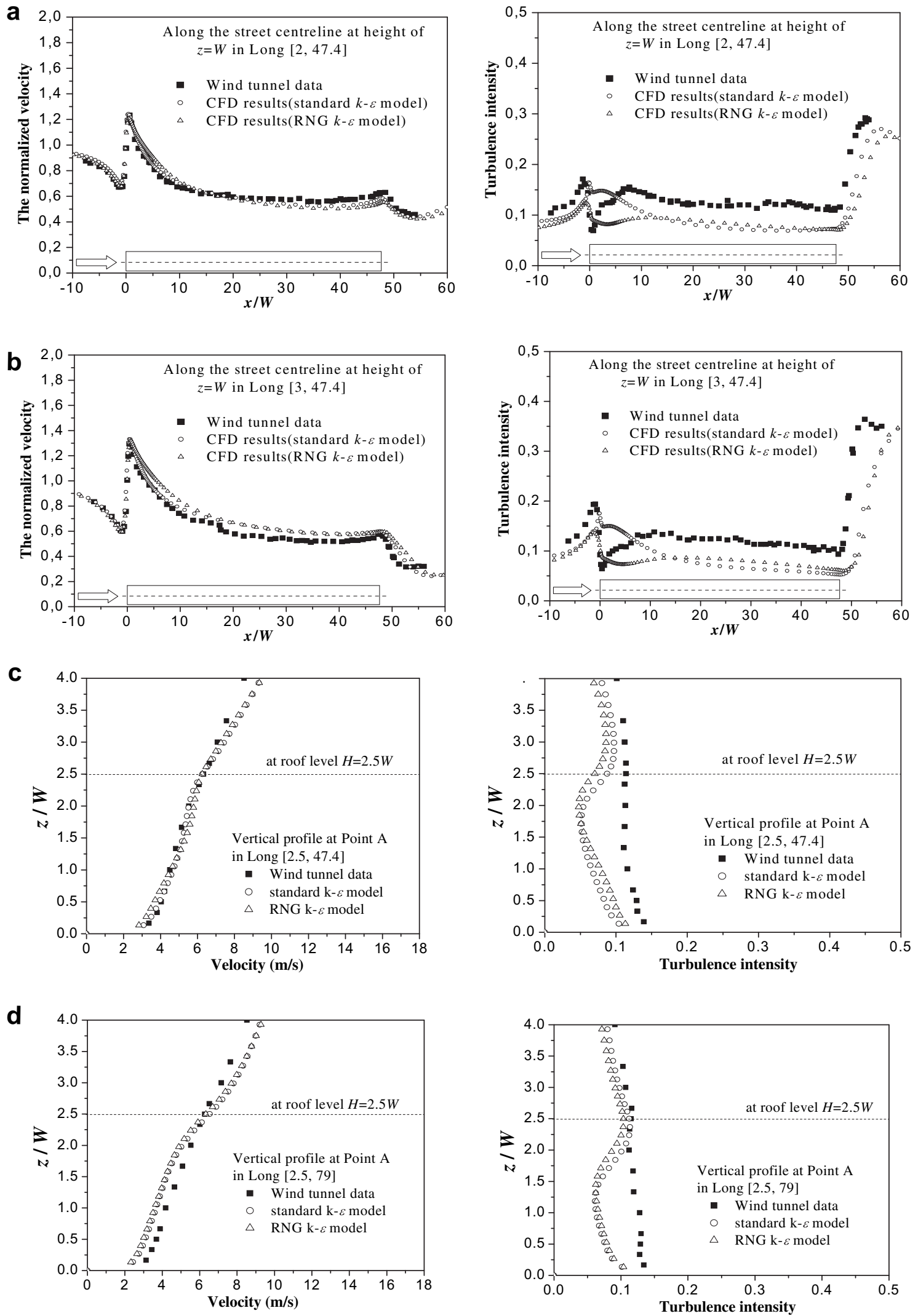

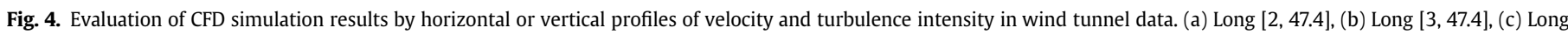
$[2.5,47.4]$ and (d) Long $[2.5,79]$. In horizontal profiles, $x=0$ denotes the location of the windward street entry. 

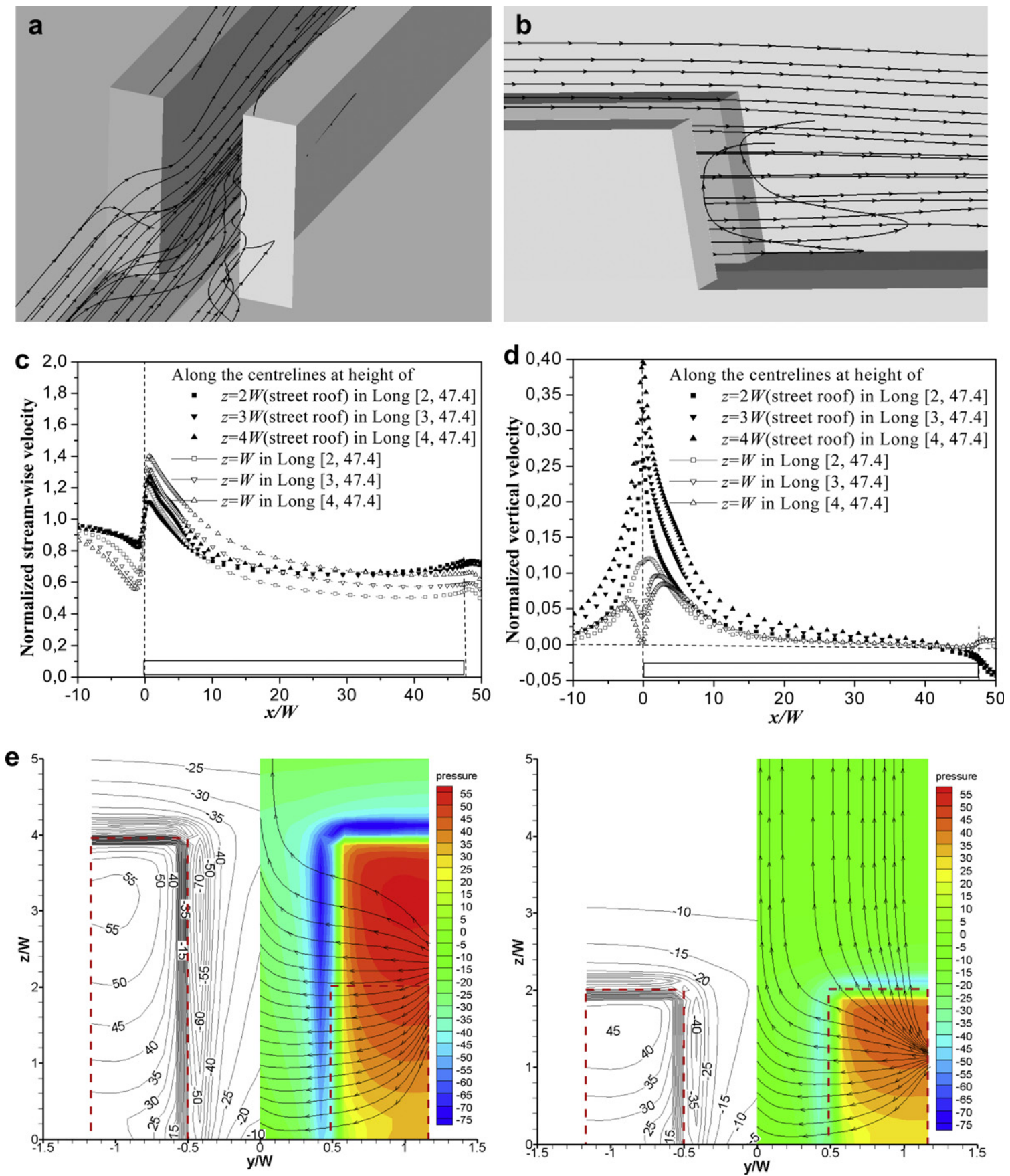

Fig. 5. (a) 3D streamline near the windward entry in Long [3, 47.4], (b) 3D streamline near the leeward entry in Long [3, 47.4]. Horizontal profiles along street centerlines in Long [2, 47.4], Long [3, 47.4] and Long [4, 47.4] at street roof levels (i.e., $z=H=2 W$ or $3 W$ or $4 W$ ) and $z=W$ : (c) normalized stream-wise velocity and (d) normalized vertical velocity. Twodimensional streamline and distribution of variables in plane of $x=-0.003 W$ (i.e. near windward street entry) in Long [2, 47.4] and Long [4, 47.4]: (e) static pressure (pa), (f) streamwise velocity $(\mathrm{m} / \mathrm{s})$ and $(\mathrm{g})$ vertical velocity $(\mathrm{m} / \mathrm{s})$. In horizontal profiles, $x=0$ denotes the location of the windward street entry.

the stagnation region to the ground. Contrast to Long [2, 47.4], more air parcels are blocked by the taller windward walls in Long $[4,47.4]$. As a result, more air parcels are driven laterally to enter the windward street entry in Long $[4,47.4]$ than those in Long $[2,47.4]$ which can be confirmed by the larger stream-wise velocity in Long $[4,47.4]$ (see Fig. 5f), meanwhile, the upward flow (the positive vertical velocity) near the roof level in Long $[4,47.4]$ and the downward flow (the negative vertical velocity) near the ground are stronger than those in Long $[2,47.4]$ (see Fig. 5g). These facts are consistent with the above findings in Fig. $5 \mathrm{c}-\mathrm{d}$.
The normalized flow rate $\left(Q^{*}\right)$ entering the windward street entry is a little more than 1.0 (see Table 1 ). Then some air parcels leaves the street volume across the street roof, which can be seen by the positive vertical velocity along the street (see Fig. 5d). As a result, the stream-wise velocity decreases (see Fig. 5c) along the street. Behind the leeward street entry $(x=47.4 \mathrm{~W})$, the resistance of street walls suddenly disappears and turbulent shear stress may transport more momentums downwardly. The downward motion across the street roof of this region brings some air parcels into the street volume which can be seen by both the flow visualization in 

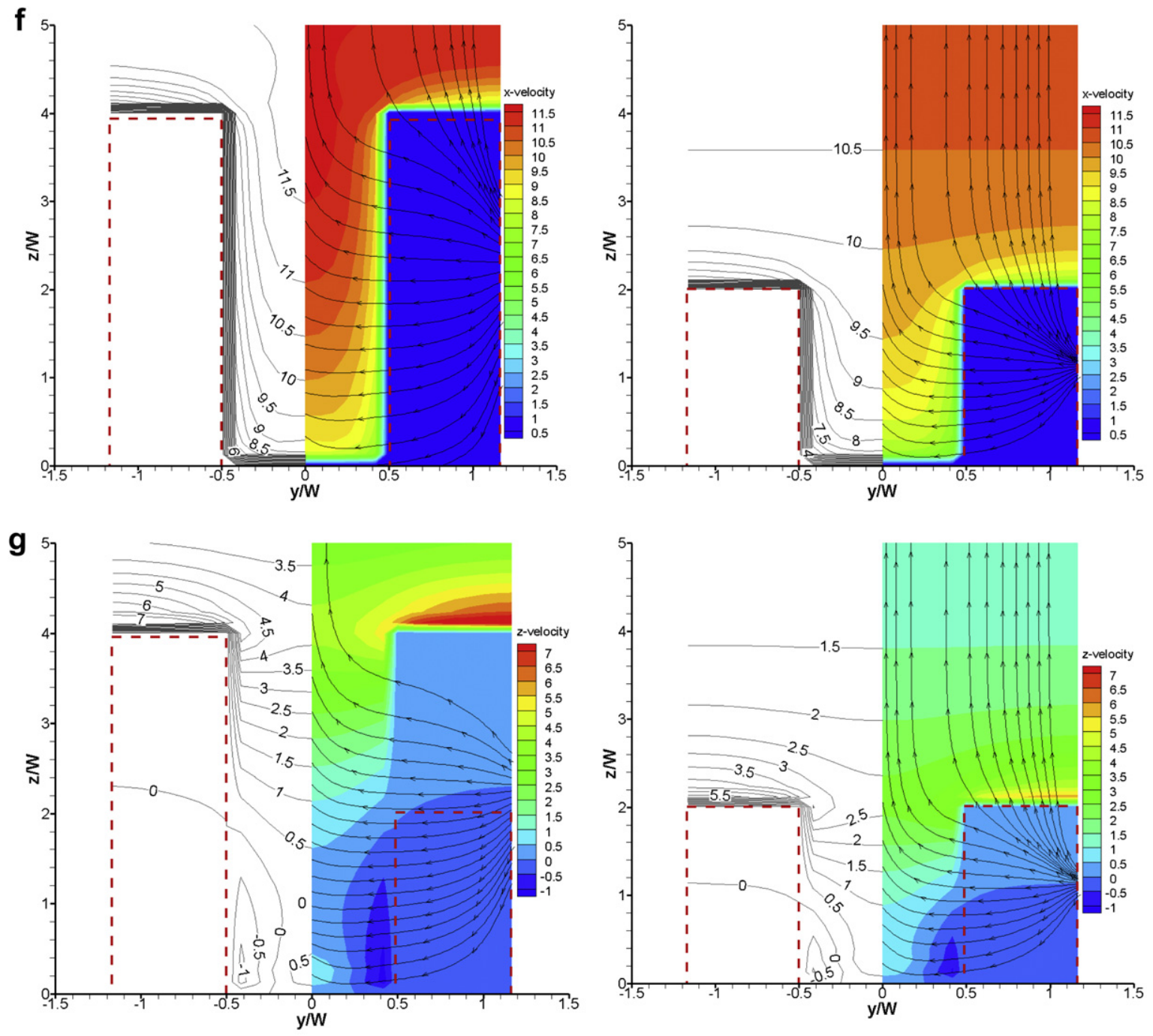

Fig. 5 (continued).

Fig. 5b and the negative vertical velocity in Fig. 5d, as a result the stream-wise velocity increases a little near the leeward street entry (at $x=47.4 W$, see Fig. 5c). In these neighborhood scale long street models (see Fig. $5 c-d$ ), the vertical velocity is positive, and the stream-wise velocity keeps decreasing until a region near the leeward street entry.

\section{Table 1}

Important parameters for fully developed region of long street models with different aspect ratios.

\begin{tabular}{|c|c|c|c|c|}
\hline Aspect ratio & $\mathrm{H} / W=2$ & $\mathrm{H} / W=2.5$ & $\mathrm{H} / W=3$ & $\mathrm{H} / W=4$ \\
\hline $\begin{array}{l}\text { Reference flow rate } \\
Q_{\infty}\left(\mathrm{m}^{3} / \mathrm{s}\right)\end{array}$ & 0.014 & 0.018 & 0.023 & 0.032 \\
\hline Area of windward entry $\left(\mathrm{m}^{2}\right)$ & 0.0018 & 0.00225 & 0.0027 & 0.0036 \\
\hline$Q^{*}$ at the windward entry & 1.02 & 1.04 & 1.06 & 1.09 \\
\hline$L f$ & $100 W$ & $140 W$ & $220 W$ & $420 W$ \\
\hline $\begin{array}{l}Q^{*} \text { in the fully developed } \\
\text { region }\end{array}$ & 0.43 & 0.38 & 0.33 & 0.27 \\
\hline $\begin{array}{l}V f^{*} \text { along the street } \\
\text { centreline at } z=W\end{array}$ & 0.41 & 0.30 & 0.23 & 0.14 \\
\hline $\begin{array}{l}V f^{*} \text { along the street } \\
\text { centreline at } z=H\end{array}$ & 0.71 & 0.68 & 0.68 & 0.70 \\
\hline
\end{tabular}

Note: $L f$ is the approximate distance from the windward opening to the starting point of the fully developed region; $V f^{*}$ is the normalized stream-wise velocity in the fully developed region.
The important findings here are that the taller long street models may capture more air parcels into the street volume for city ventilation. In addition, the flow cannot be fully developed along a neighborhood scale long street model, so the flow rate along the street always varies. Then we will study the flow in the city scale long street models.

\subsection{Effect of street length in long streets with the same aspect ratio $(H / W=2)$}

We also studied what happens if the street length increases from a neighborhood scale $(L / W=47.4$ or 79$)$ to a city scale $(L / W=333)$.

Fig. 6 shows that the horizontal profiles of four variables along the street centerlines in Long [2, 47.4], Long [2, 79], Long [2, 333]. The horizontal profiles of all the variables are almost the same in the upstream region $(-10<x / W<35)$, showing that wind in the upstream region $(-10<x / W<35)$ is affected little when the street length changes. Most importantly, there is an obvious fully developed region existing in the city scale long street model (Long $[2,333])$, where all the variables keep constant. The flow variables along the street centerlines at $z=2 W$ (the street roof level) seems to become steady earlier than those at $z=W$, because the former 

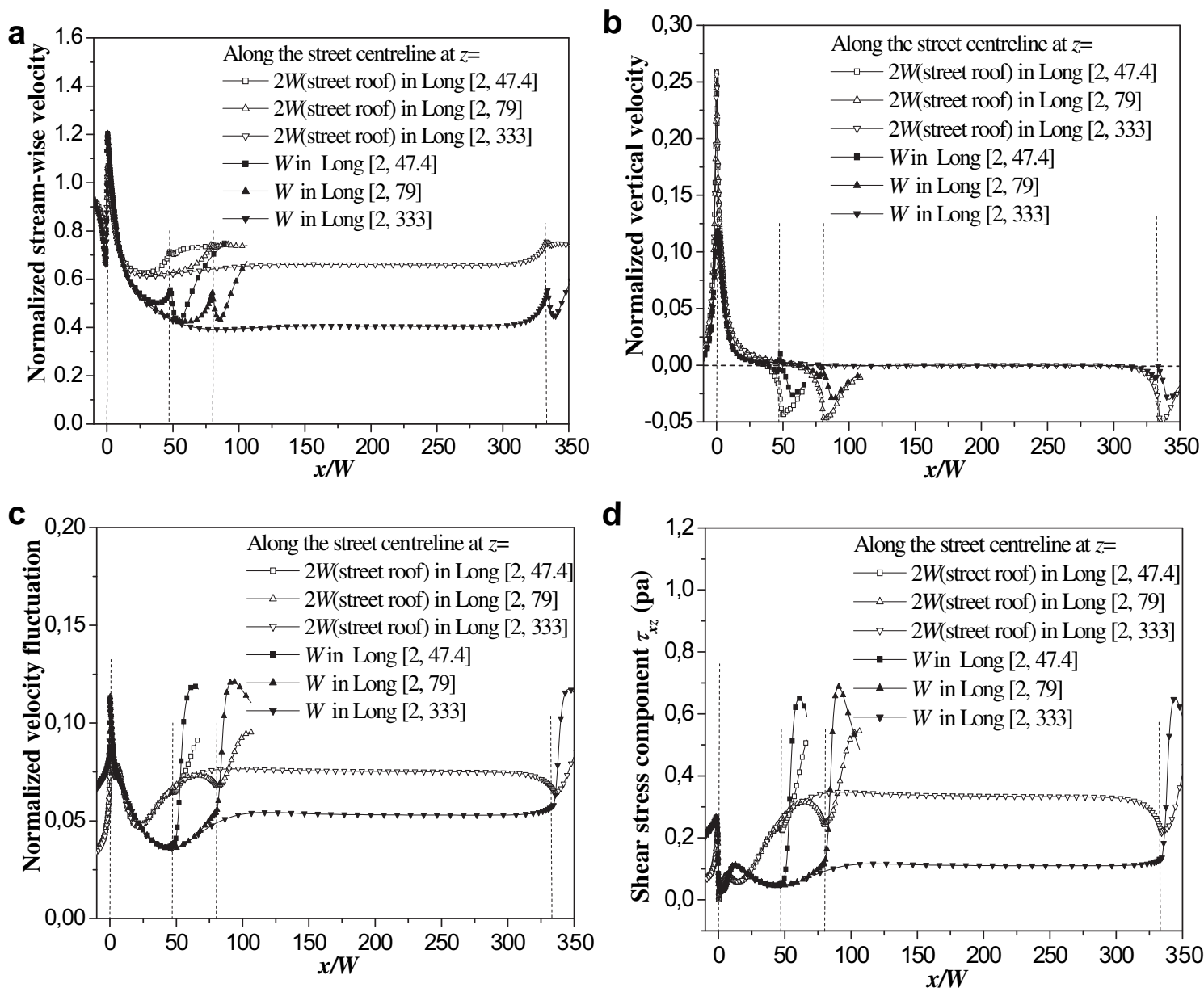

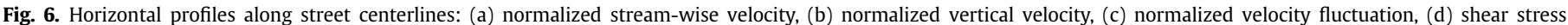
component $\tau_{\mathrm{xz}}$ in Long $[2,47.4]$, Long $[2,79]$, Long $[2,333] . x=0$ denotes the location of the windward street entry.

is affected by the shear stress of the external flow above the street roof more directly. We define the location of $x / W=100$ as the approximate beginning point of the fully developed region. In this region, the downward momentum shear stress component is nearly positive constant which act as a motor for the constant stream-wise motion along the street (see Fig. 6a and d). In addition, the vertical velocity is nearly zero (see Fig. 6b) and the vertical velocity fluctuation $\left(\sigma_{w}=\sqrt{\overline{w^{\prime} w^{\prime}}}=\sqrt{2 k / 3}\right)$ is not zero (see Fig. 6c), confirming that turbulent fluctuation across street roofs is more important than mean flows for air exchange in the fully developed region. Near the leeward street entry $(x / W=47.4$, 79 or 333), some air enters the street volume downwardly (i.e. the negative vertical velocity in Fig. 6b) across street roofs, resulting in an accelerated process of the stream-wise velocity (see Fig. 6a).

\subsection{Effect of aspect ratio in city scale long street models $(L / W=333$ or 667$)$}

Since it's confirmed that there is a fully developed region in a city scale long street model with the aspect ratio of 2 , we here aim to study what happens in a city scale long street model $(L / W=333$ or 667) when the model become taller.

Fig. 7 shows that the horizontal profiles of the stream-wise velocity and the velocity fluctuation along the street centerlines in Long [2,333], Long [2.5, 333], Long [3, 333] and Long [4, 333]. We find that, the starting point of the fully developed region in Long [2.5, $333]$ is about $x=140 \mathrm{~W}$ and that in Long $[3,333]$ is about $x=220 \mathrm{~W}$.
The normalized stream-wise velocities in the fully developed region along the street centerlines at the height of $z=W$ in Long [2, 333], Long $[2.5,333]$, Long $[3,333]$ are about $0.41,0.30,0.23$, and those at the height of $z=H$ (i.e. roof levels) are about $0.70,0.68,0.68$. These facts confirm that, in the fully developed region of long street models with different aspect ratios, wind at the street roof level almost keeps a steady relation to wind in the far upstream free flow at the same height level, however wind far below the street roof (i.e. at $z=W$ ) may be various and it becomes weaker in a taller long street. In the fully developed region, the velocity fluctuation at $z=W$ in a taller long street is also weaker than that in a lower one. In Long $[4,333]$, it is difficult to conclude that a constant flow condition exists because the points where the stream-wise velocity stops decreasing are near the leeward street entry.

To show the process to set up a constant flow condition in the long street model with an aspect ratio of 4 , we studied a longer street model (Long $[4,667])$. Fig. 8 shows the horizontal profiles in Long [3, 333], Long [4, 333], Long [3, 667] and Long [4, 667]. It's found that, for the long street model with an aspect ratio of 4 , the constant flow conditions of the stream-wise velocity and the velocity fluctuation in Long $[4,667]$ start at about $x / W=420$. The normalized streamwise velocity at the height of $z=W$ in the fully develop region of Long $[4,667]$ is about 0.14 , which is smaller than that in Long $[3,667]$ (i.e. 0.23 ). In the same region, the velocity fluctuation at $z=W$ in Long $[4,667]$ is also smaller than that in Long $[3,667]$.

The important findings here are that there is always a fully developed region with constant flow conditions if the street is 
a
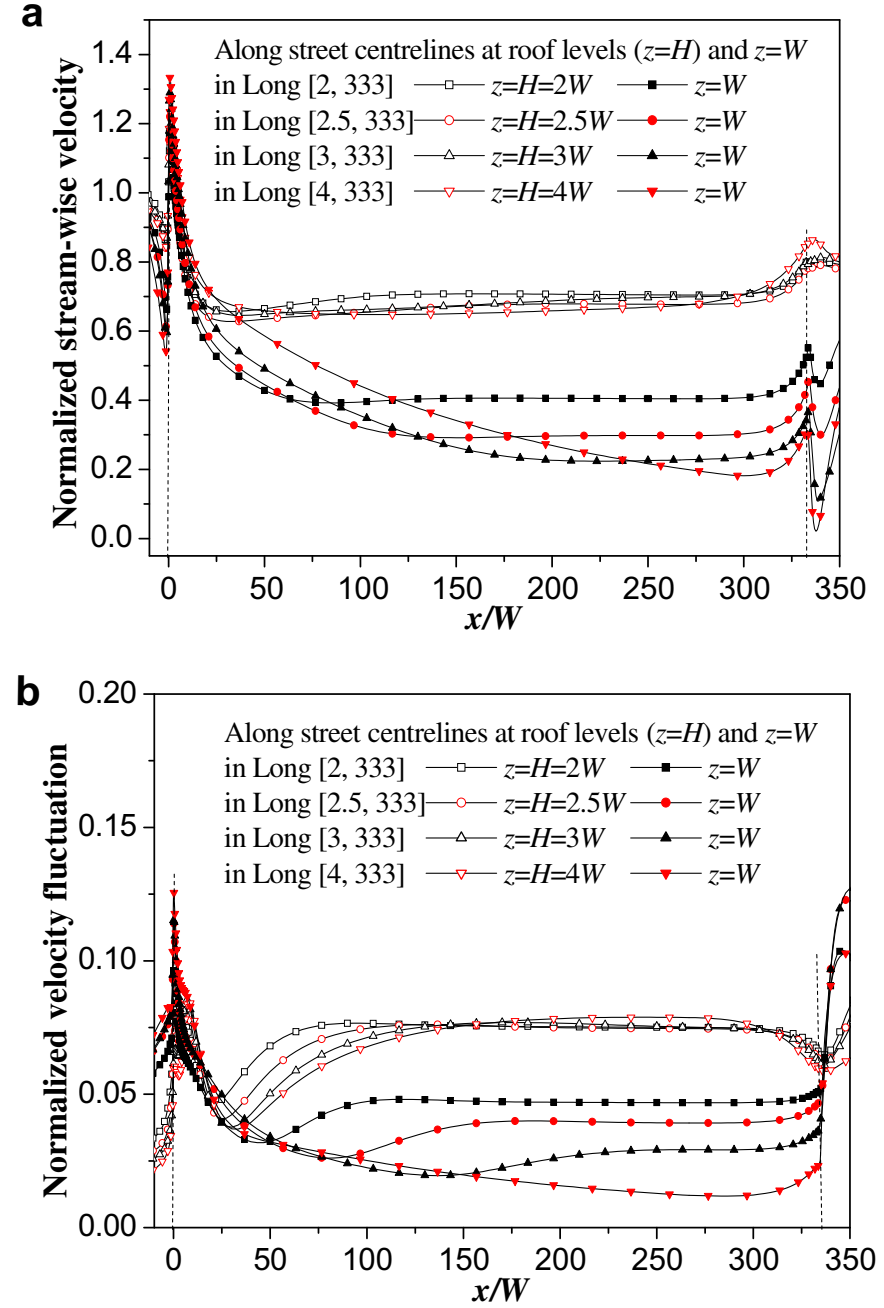

Fig. 7. Horizontal profiles along street centerlines: (a) normalized stream-wise velocity, (b) normalized velocity fluctuation in Long [2, 333], Long [2.5, 333], Long [3, 333], Long [4, 333]. $x=0$ denotes the location of the windward street entry.

sufficiently long and the positive stream-wise flow never stops. The street aspect ratio has an important impact on the balance flow rate and the distance to reach a balance. We summarized all the important parameters for the city scale long street models in Table 1. The normalized flow rate through the windward street entry is a little more than 1.0 for all the models. The approximate distances from the windward entry to the starting point of the fully developed region $(L f)$ and the normalized horizontal flow rates $\left(Q^{*}\right)$ in the fully developed region are different: If the long street model become taller, the distance $(L f)$ for establishing the constant flow conditions increases (i.e. $L f / W=100,140,220,420$ ) and the normalized horizontal flow rate in the fully developed region decreases (i.e. $Q^{*}=0.43,0.38,0.33,0.27$ ). The normalized velocities along the street centerlines in the fully developed region $\left(V f^{*}\right)$ at roof levels $z=H$ are affected little by the street height (i.e. about 0.7 ), however, those $\left(V f^{*}\right)$ at $z=W$ decrease (i.e. from 0.41 to 0.14 ) with the increasing street height.

\subsection{Analysis of ventilation flow rates and air exchange rates}

Flow rates across street roofs are important for the flow rate flushing through the street volume for pollutant dilutions. The air change rate may show the ventilation capacity which is decided by the magnitude of the street volume and the flow rates through
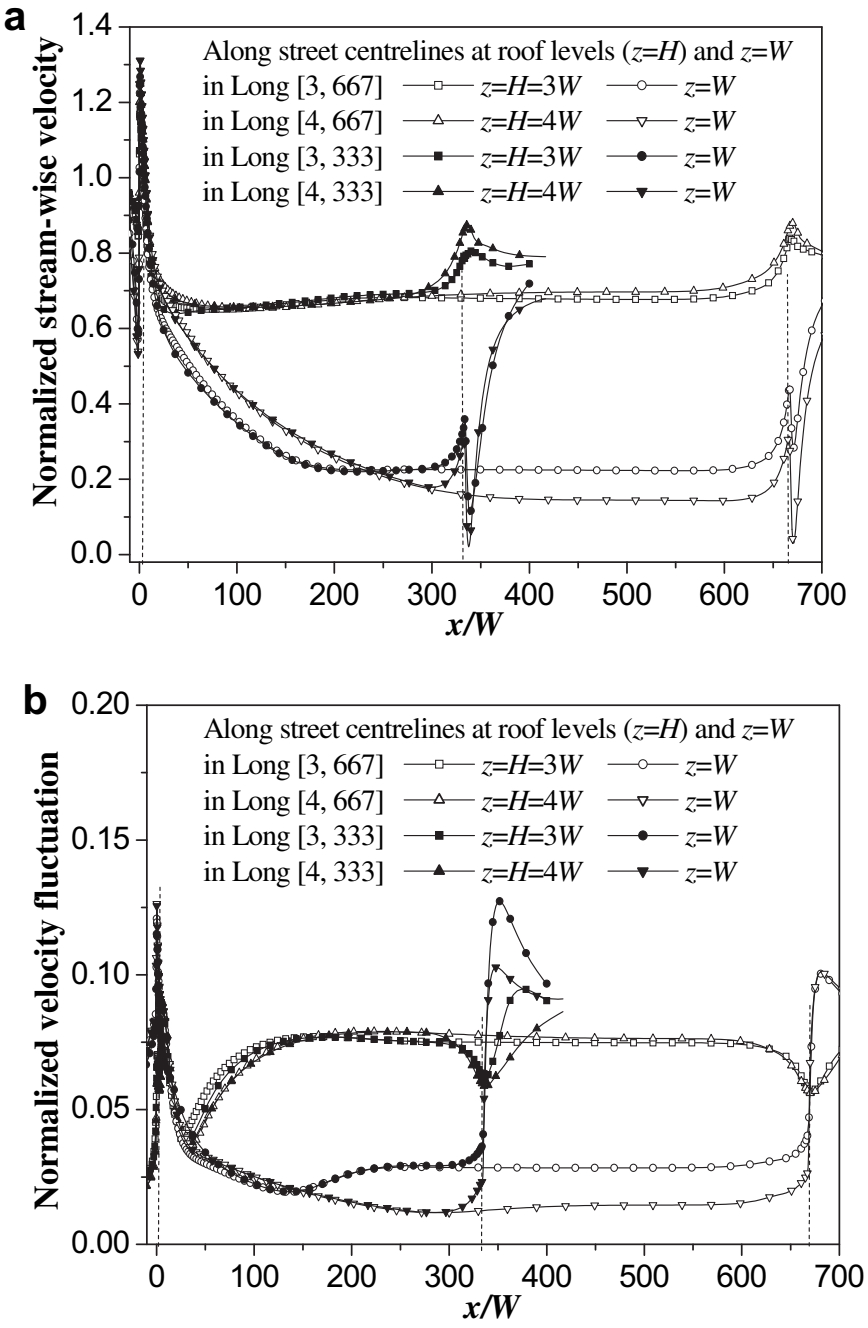

Fig. 8. Horizontal profiles along street centerlines. (a) normalized stream-wise velocity, (b) normalized velocity fluctuation in Long [3, 333], Long [4, 333], Long [3, 667], Long $[4,667] . x=0$ denotes the location of the windward street entry.

street openings and street roofs due to mean flows and turbulent fluctuations.

Fig. 9 shows the normalized vertical flow rates by upward motion, downward motion and their total effect, as well as the effective flow rate due to turbulent exchange across the street roof in all the test cases. For the long street models with the same aspect ratio, Fig. 9a shows that, since the constant flow conditions is not established for the neighborhood scale models $(47.4 \mathrm{~W}$ or $79 \mathrm{~W})$, the upward flow rate increases a little and more air parcels continue leaving the street volume upwardly when the street length increases (i.e. from $47.4 \mathrm{~W}$ to $79 \mathrm{~W}$ ). Similarly the downward flow rate also increases a little as the street length increases from $47.4 \mathrm{~W}$ to $79 W$, because the strength of downward motion near the leeward entry is affected by the strength of upward motion in its upstream region and such upward motion may become weaker when the constant flow condition has not been established but the street becomes longer. The extreme example of such situation is that (see Fig. 9a), the downward flow rates in the city scale long street models ( $333 \mathrm{~W}$ or $667 \mathrm{~W}$ ) may be several times of those in the neighborhood scale long street models. For those city scale long street models with aspect ratios of 2, 2.5, and 3, when the street become longer (from $333 \mathrm{~W}$ to $667 \mathrm{~W}$ ), both the upward and downward flow rates across the street roof change little. It confirms that no more air parcels leave upwardly or enter downwardly 

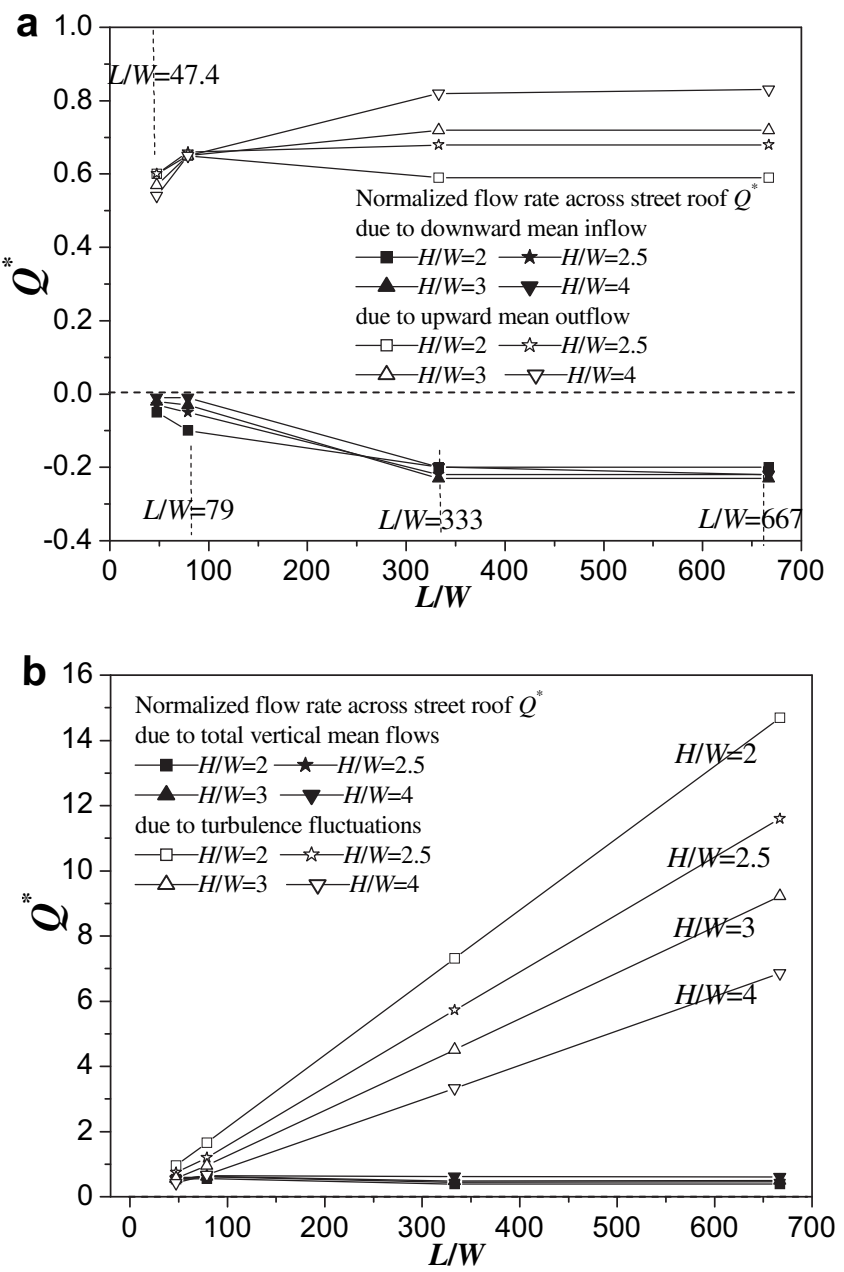

Fig. 9. Normalized vertical flow rates due to mean flows and normalized effective flow rate due to turbulent exchange across street roof. (a) due to upward mean flow and due to downward mean flow, and (b) due to the total vertical mean flows and due to turbulence fluctuation. Note that, the reference flow rates for normalization have different values when street aspect ratios are different (see Table 1). In Fig. 9a, positive value means downward inflow rate and negative value denotes upward outflow rate.

across the street roof when the city scale street length increases. For Long [4, 667] and Long [4, 333], the upward and downward flow rates change a little because the flow balance is not established in Long $[4,333]$. Fig. 9b shows that for all the long street models with the same height, the effective flow rate due to turbulent exchange across the street roof almost keeps the same increasing rate with the increasing street length. For the neighborhood scale long street models, the effective flow rate due to such turbulent exchange is the same order with those due to the total vertical mean flows (upward and downward), however in the city scale long street models, the former may be many times of the latter.

Fig. 10 shows the air change rates $(A C H)$ by the total mean flow rates through openings and the street roof and that due to turbulent exchange across the street roof. The air change rates for these models are very large because the idealized models in wind tunnel are small. For the street models with the same height, $A C H$ by the total mean flow rates decreases quickly when the street becomes longer. It is because that the control street volume increases at the same rate with the increasing street length but the total mean flow rates only change a little. For example, $A C H$ by the total mean flow rates in those models with the street length of $667 \mathrm{~W}$ are almost half of those with the street length of $333 W$. ACH due to turbulent exchange across the street roof

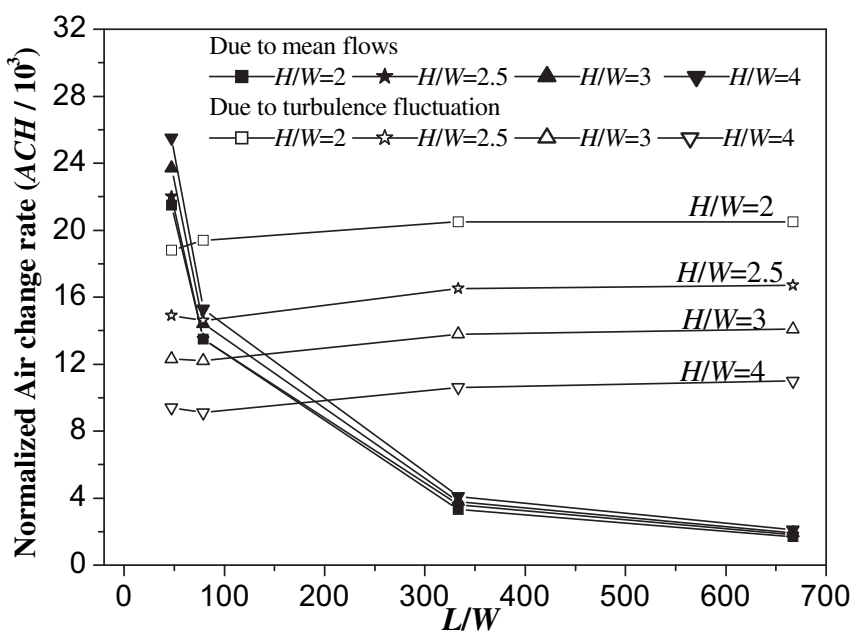

Fig. 10. Air change rate $(A C H)$ due to mean flows across all the openings and the street roof and that $\left(\mathrm{ACH}_{\text {turb }}\right)$ due to turbulent exchange across the street roof. $L$ is total street length and $W$ is street width.

change little when the street length changes from $333 \mathrm{~W}$ to $667 \mathrm{~W}$ and they are much larger than those due to the total mean flow rates. In the city scale long street models, the air change rate due to turbulence fluctuations can be 5-10 times greater than that due to the mean flows.

\section{Conclusion}

We studied wind conditions in the neighborhood scale or city scale long street models with aspect ratios of 2-4. The models act as obstacles and pathways to the parallel approaching wind. CFD simulations were evaluated by wind tunnel data, then we analyzed the flow mechanisms and ventilation capacity in these long street models.

It's found that taller street models may capture more air parcels at the windward entry and the normalized penetrating flow rate through it is a little more than 1.0 for all street models. As deeper into the long street, a significant amount of air leaves the street volume upwardly across the street roof, as a result the stream-wise velocity decreases along the street. If the street models are sufficiently long, this process continues until that a constant flow condition is established in the fully developed region where the stream-wise velocity keeps constant and the vertical velocity is zero. In such a region, when the model become taller, wind at the roof level change little but wind far below the roof level is weakened, as a result, the balance flow rate is smaller in a taller long street model. In addition, the distance to establish such a flow balance in the taller model is much longer than that in the lower one. Near the leeward street entry, a downward flow across the street roof appears and the flow rate along the street model increases a little.

For the neighborhood scale long street models, the air change rate by mean flows is much larger than that in a city scale one because the smaller street volume in the former. In addition, in the neighborhood scale long street models, turbulence fluctuation across street roofs contribute to air exchange the same order with that due to mean flows across street entries and street roofs. However in the city scale long street models, the turbulence exchange rate can be 5-10 times greater than the mean flow rate. It confirms that turbulent exchange across the street roof is more important to air exchange in the city scale long street models.

The wind reduction and characteristics of ventilation in all these long street models has important implication to city ventilation in a high-rise long city like Hong Kong. This paper confirms that, since people have to build tall buildings in the crowded urban area of 
Hong Kong, the urban design of tall buildings is not the definitely worse choice for the city ventilation. The ventilation capacity is decided not only by the building height but also the total city length and the street width. A good choice is to build taller buildings and wider streets to capture more air into the street network for city ventilation, at the same time, to utilize some large open space like gardens, football fields, parks etc to separate a continuously city scale (up to $10 \mathrm{~km}$ ) built-up urban area into several neighborhood scale (up to 1-2 km) urban areas.

\section{Acknowledgements}

This work was supported by a grant from the Research Grants Council of the Hong Kong SAR Government (Project No. HKU 7145/ 07E). The help by Mr. R Peltary with building wind-tunnels models, Mr. H Lundstom with the measuring equipment 1 , all from the University of Gävle, is gratefully acknowledged. We also thank two anonymous reviewers for their constructive comments which have improved this paper.

\section{Nomenclature}

$A, A_{\text {roof }}$ area of street openings and the street roof

$A C H, A C H_{\text {turb }}$ air change rate by mean flows and due to turbulent exchange on street roofs

$H, L, W$ street height, street length and street height

$k, \varepsilon \quad$ turbulent kinetic energy and its dissipation rate
I turbulence intensity

$l_{t} \quad$ turbulent characteristic length scale

$\sigma_{\mathrm{w}} \quad$ verticalvelocity fluctuation

$\vec{n} \quad$ normal direction of street opening or the street roof

$p \quad$ static pressure

$Q_{\infty} \quad$ reference flow rate far upstream

$Q^{*} \quad$ normalized flow rate through street openings or the street roof

$Q_{\text {turb } \pm}^{*} \quad$ normalized effective flow rate through street roofs due to turbulent exchange

$\bar{u}, \bar{v}, \bar{w} \quad$ stream-wise, span-wise and vertical velocity components in $x, y, z$ directions

$u^{\prime}, v^{\prime}, w^{\prime} \quad$ stream-wise, span-wise, vertical velocity fluctuations

$\bar{u}_{\infty} \quad$ horizontal velocity far upstream

$\vec{V}, V \quad$ velocity vector and velocity magnitude

vol control street volume

$L f, V f^{*}$ approximate distance fromwindward entries to starting point of fully developed region and normalized streamwise velocity in this region.

$\rho \quad$ density of air

$\mu, \mu_{t} \quad$ molecular viscosity and turbulent viscosity

$x, y, z \quad$ stream-wise, span-wise and vertical directions

$\tau_{x z} \quad$ downward turbulent shear stress component

Appendix A. A map of buildings in some urban areas of Hong Kong and a corresponding idealized box model with groups of buildings and street network or a long street model

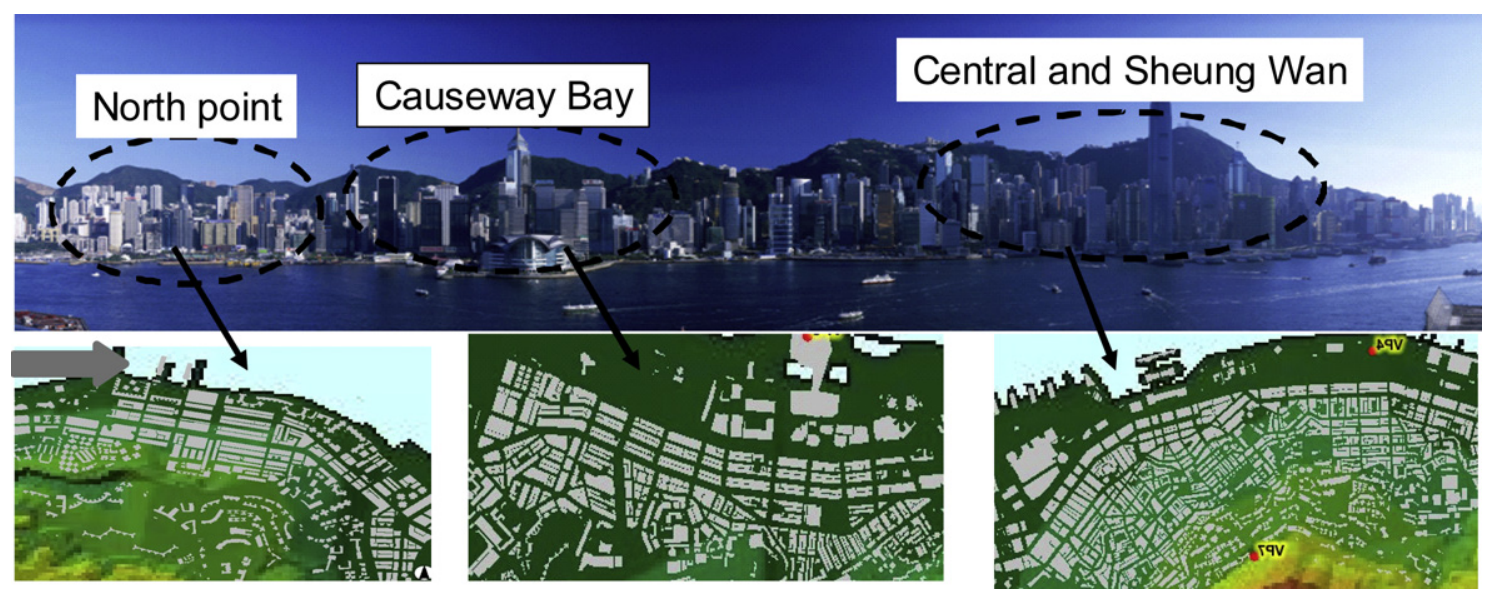

Fig. A.1 A map of buildings in some urban areas of Hong Kong (from the Department of Geography, the University of Hong Kong).
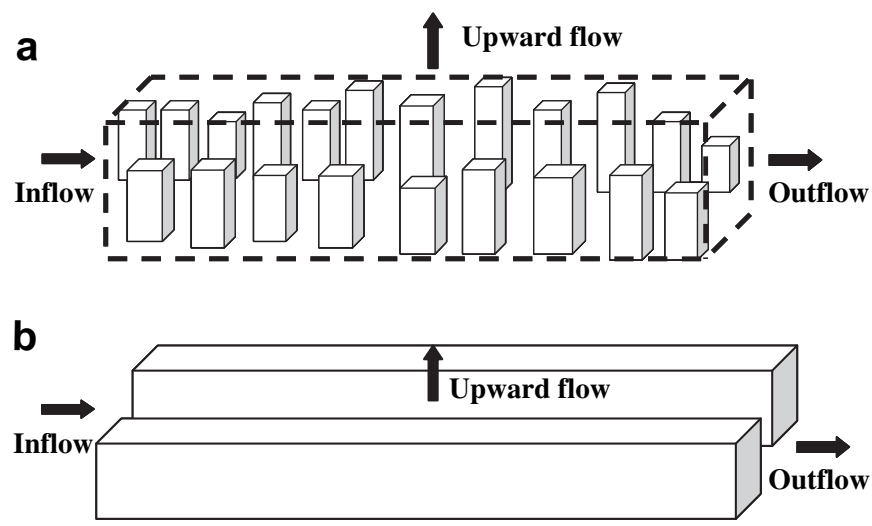

Fig. A.2 An idealized box model of urban ventilation: (a) For an urban canopy with groups of buildings and street networks, (b) for a long street model. 


\section{References}

[1] Britter RE, Hanna SR. Flow and dispersion in urban areas. Annals of Review of Fluid Mechanics 2003;35:469-96.

[2] Tong H, Walton A, Sang JG, Chan JCL. Numerical simulation of the urban boundary layer over the complex terrain of Hong Kong. Atmospheric Environment 2005;39(19):3549-63.

[3] Li Y, Stathopoulos T. Numerical evaluation of wind-induced dispersion of pollutants around a building. Journal of Wind Engineering and Industrial Aerodynamics 1997;67-68:757-66.

[4] Oke TR. Street design and urban canopy layer climate. Energy and Buildings 1988;11(1-3):103-13.

[5] Sini JF, Anquetin S, Mestayer PG. Pollutant dispersion and thermal effects in urban street canyons. Atmospheric Environment 1996;30(15):2659-77.

[6] Baik JJ, Kim JJ. On the escape of pollutants from urban street canyons. Atmospheric Environment 2002;36(3):527-36.

[7] Xie XM, Huang Z, Wang J. The impact of urban street layout on local atmospheric environment. Building and Environment 2006;41(10):1352-63.

[8] Li XX, Liu CH, Leung DYC. Numerical investigation of pollutant transport characteristics inside deep urban street canyons. Atmospheric Environment 2009;43(15):2410-8.

[9] MacDonald RW, Griffiths RF, Cheah SC. Field experiments of dispersion through regular arrays of cubic structures. Atmospheric Environment 1997;31(6):783-95.
[10] Hanna SR, Tehranian S, Carissimo B, Macdonald RW, Lohner R. Comparisons of model simulations with observations of mean flow and turbulence within simple obstacle. Atmospheric Environment 2002;36(32):5067-79.

[11] Cheng Y, Lien FS, Yee E, Sinclair R. A comparison of large Eddy simulations with a standard $k-\epsilon$ Reynolds-averaged Navier-Stokes model for the prediction of a fully developed turbulent flow over a matrix of cubes. Journal of Wind Engineering and Industrial Aerodynamics 2003;91(11):1301-28.

[12] Hamlyn D, Britter R. A numerical study of the flow field and exchange processes within a canopy of urban-type roughness. Atmospheric Environment 2005;39(18):3243-54.

[13] Ahmad K, Khare M, Chaudhry KK. Wind tunnel simulation studies on dispersion at urban street canyons and intersections-a review. Journal of Wind Engineering and Industrial Aerodynamics 2005;93(9):697-717.

[14] Belcher SE. Mixing and transport in urban areas. Royal Society of London Transactions Series A 2005;363:2947-68.

[15] Soulhac L, Perkins RJ, Salizzioni P. Flow in a street canyon for any external wind direction. Boundary-Layer Meterology 2008;126(1):365-88.

[16] Hang J, Sandberg M, Li YG. Effect of urban morphology on wind conditions in idealized city models. Atmospheric Environment 2009;43(4):869-78.

[17] Choudhury D. Introduction to the renormalization group method and turbulence modeling. Technical Memorandum TM-107. Fluent Inc; 1993.

[18] Launder BE, Spalding DB. The numerical computation of turbulent flows. Computer Methods in Applied Mechanics and Engineering 1974;3:269-89.

[19] Fluent 6.2 user's manual, http://www.fluent.com; 2005. 